\title{
PENGGUNAAN MESIN INDUK PADA ALAT TANGKAP PURSE SEINE DI KM. SURYA JAYA
}

\section{APPLICATION MAIN ENGINE OF CATCHING EQUIPMENT PURSE SEINE AT KM. SURYA JAYA}

\author{
Boby Wisely Ziliwu ${ }^{1 *}$, Iskandar Musa ${ }^{1}$, Roma Yuli F Hutapea ${ }^{1}$, Hafiz Ziddin ${ }^{1}$ \\ ${ }^{1}$ Politeknik Kelautan dan Perikanan Dumai, JI. Wan Amir, No.1, Kelurahan Pangkalan Sesai, \\ Kecamatan Dumai Barat, Kota Dumai, Provinsi Riau, Indonesia \\ "Korespondensi: bobyziliwu@gmail.com (BW Ziliwu) \\ Diterima 22 Agustus 2020 - Disetujui 17 September 2020
}

\begin{abstract}
ABSTRAK. Tujuan penelitian yaitu untuk mengetahui penggunaan mesin induk pada alat tangkap purse seine di KM. Surya Jaya. Mesin yang digunakan di kapal KM. Surya Jaya baik mesin induk maupun mesin penggerak motor adalah jenis mesin diesel. Mesin Diesel merupakan motor bakar dengan proses pembakaran yang terjadi didalam mesin itu sendri (Internal Combustion engine) dan pembakaran terjadi karena udara murni dimampatkan (dikompresi) dalam suatu ruang bakar (silinder) sehingga diperoleh udara bertekanan tinggi serta panas yang tinggi, bersamaan dengan itu disemprotkan / dikabutkan bahan bakar sehinga terjadiah pembakaran. Perbedaan antara mesin penggerak utama menggunakan jumllah silinder V-8 dan mesin penggerak generator menggunakan jumlah silinder 6 dan antara mesin penggerak utama dan mesin penggerak generator memiliki sistem pendingin yang sama yaitu sistem pendingin terbuka, memiliki sistem bahan bakar yang sama dialiri dengan bahan bakar solar dari tangki yang sama dan penyaring minyak yang sama. Mesin induk dapat digunakan untuk menggerakan tenaga listrik untuk penerangan dalam aktifitas pengoperasian alat tangkap purse seine.
\end{abstract}

KATA KUNCl: Mesin induk, mesin generator, purse seine

ABSTRACT. The research objective was to determine the use of the main engine in the purse seine fishing gear at KM. Surya Jaya. The machine used on the KM Surya Jaya the main engine and the motor drive engine is a type of diesel engine. Diesel engine is a combustion engine with a combustion process that occurs inside the engine it self (Internal Combustion engine) and combustion occurs because pure air is compressed (compressed) in a combustion chamber (cylinder) to obtain high pressure air and high heat, at the same time it is sprayed / atomized fuel so that combustion occurs. The difference between the main propulsion engine uses the number of cylinder V-8 and the generator propulsion uses the number of cylinders 6 . And between the main propulsion engine and the generator propulsion has the same cooling system that is an open cooling system, has the same fuel system flowed with diesel fuel from the same tank and the same oil filter. The main engine can be used to drive electric power for lighting in purse seine fishing gear operation activities.

KEYWORDS: Main engine, generator engine, purse seine

\section{Pendahuluan}

Sibolga terletak di pantai Barat Sumatera Utara. Jaraknya lebih kurang 344 km dari Kota Medan, ibu kota Provinsi Sumatera Utara. Kota ini berada pada sisi pantai Teluk Tapian Nauli menghadap ke arah lautan Hindia. Bentuk Kota memanjang dari Utara ke Selatan mengikuti garis pantai. Sebelah Timur terdiri dari gunung dan sebelah Barat adalah lautan. Lebar kota yaitu jarak dari garis pantai ke 
pegunungan sangat sempit hanya lebih kurang 500 meter sedangkan panjangnya adalah $8.520 \mathrm{~km}$. (BPS Sibolga, 2019).

Laut sebagai tempat aktifitas perikanan dimana penangkapan berbagai macam ikan, berbagai macam peralatan penangkapan ikan, berbagai teknik penangkapan ikan dan berbagai lokasi penangkapan ikan yang menghasilkan beragam macam hasil perikanan. Di samping itu ikan yang memiliki potensi besar pada perairan Samudera Hindia adalah ikan pelagis jenis tongkol sebagai hasil tangkapan utama para nelayan. Tepatnya nelayan di daerah Sibolga yang menggunakan alat tangkap pukat cincin (purse seine) dimana alat tangkap tersebut sangat strategis untuk penangkapan jenis ikan pelagis yaitu ikan tongkol. Sifat dari ikan pelagis jenis ikan tongkol yaitu cenderung bergerombolan menjadikan alat tangkap purse seine lebih efektif. Prinsip pengoperasian purse seine ditujukan untuk menangkap ikan pelagis yang bergerombol dengan cara melingkari gerombolan ikan, kemudian bagian bawah jaring dikerutkan dengan menarik tali kerut (purse line) melalui cincin-cincin yang terdapat pada bagian tali ris bawah dan jaring akan berbentuk seperti mangkuk. Pengoperasian alat tangkap tidaklah berjalan lancar tanpa ada bantuan dari peralatan mesin seperti mesin induk sebagai alat utama penggerak kapal, mesin gilingan tali atau trol sebagai penarik tali dari alat tangkap, alat navigasi sebagai alat bantu aktifitas navigasi dan beserta alat bantu di atas kapal lainnya yang berfungsi sebagai penyempurnaan aktifitas di atas kapal. Berbagai macam alat bantu tersebut haruslah berfungsi dengan baik agar tidak mengganggu aktifitas dan menghambat aktifitas yang dilaksanakan di atas kapal. Pengecekan, perbaikan, dan peninjauan setiap alat bantu di atas kapal harus di awasi sedemikian rupa maka dari itu perlu ketenaga ahlian khusus dalam 2 menangani hal tersebut dengan tujuan mampu mengatasi permasalahan yang ada pada alat bantu di atas kapal. Penelitian ini memiliki beberapa tujuan yaitu, mengetahui mesin induk di kapal KM. Surya Jaya, mengoperasikan mesin listrik yang terdapat pada KM. Surya Jaya dan mengetahui bagaimana merawat mesin induk yang diatas kapal. Tujuan penelitian yaitu untuk mengetahui penggunaan mesin induk pada alat tangkap purse seine di KM. Surya Jaya.

\section{Bahan dan Metode}

Pelaksanaan penelitian dilaksanakana pada tanggal 30 November 2019 sampai dengan 26 Desember 2019. Dalam jangka 20 hari melakukan 2 kali operasi (trip) dengan sekali operasi kurang lebih 8 sampai 12 hari. Analisis data yang digunakan yaitu dengan memperoleh informasi yang berkaitan dengan kegiatan penelitian ini di kapal purse seine.

Mesin diesel adalah motor bakar dengan proses pembakaran yang terjadi didalam mesin itu sendiri (internal combustion engine) dan pembakaran terjadi karena udara murni dimampatkan (dikompresi) dalam suatu ruang bakar (silinder) sehingga diperoleh udara bertekanan tinggi serta panas yang tinggi, bersamaan dengan itu disemprotkan/dikabutkan bahan bakar sehingga terjadilah pembakaran (Kusairi, 2018). Pembakaran yang berupa ledakan akan menghasilkan panas mendadak naik dan tekanan menjadi tinggi didalam ruang bakar. Tekanan ini mendorong piston kebawah yang berlanjut dengan poros engkol berputar. Sesuai dengan gerakan piston untuk mendapatkan satu kali proses tersebut maka mesin diesel tersebut dibagi dalam 2 macam:

a. Mesin diesel 4 langkah (4 Tak)

Mesin diesel dimana setiap satu kali proses usaha menjadi 4 kali langkah piston atau 2 kali putaran poros engkol.

b. $\quad$ Mesin diesel 2 langkah (2 Tak)

Mesin diesel dimana setiap satu kali proses usaha menjadi terjadi 2 kali langkah piston atau satu kali putaran poros engkol.

Prinsip kerja mesin diesel 4 tak sebenarnya sama dengan prinsip kerja mesin otto atau mesin bensin, yang membedakan adalah cara memasukkan bahan bakarnya. Pada mesin diesel bahan bakar disemprotkan langsung ke ruang bakar dengan menggunakan injector. Proses mesin diesel 4 langkah yang dimaksud adalah: 
Aurelia Journal, Vol. 2 (1): 9-18

a) Langkah Isap

Pada langkah ini piston bergerak dari TMA (Titik Mati Atas) ke TMB (Titik Mati Bawah). Saat piston bergerak ke bawah katup isap terbuka yang menyebabkan tekanan udara di dalam silinder seketika lebih rendah dari tekanan atmosfer, sehingga udara murni langsung masuk ke ruang silinder melalui filter udara.

b) Langkah Kompresi

Pada langkah ini piston bergerak dari TMB menuju TMA dan kedua tertutup. Karena udara yang berada di dalam silinder didesak terus oleh piston, menyebabkan terjadi kenaikan tekanan dan temperatur, sehingga udara di dalam silinder menjadi sangat panas. Beberapa derajat sebelum piston mencapai TMA, bahan bakar di semprotkan ke ruang bakar oleh injector yang berbentuk kabut.

c) Langkah Usaha

Pada langkah ini kedua katup masih tertutup, akibat semprotan bahan bakar di ruang bakar akan menyebabkan terjadi ledakan pembakaran yang akan meningkatkan suhu dan tekanan di ruang bakar Tekanan yang besar tersebut akan mendorong piston ke bawah yang menyebabkan terjadi gaya aksial. Gaya aksial ini dirubah dan diteruskan oleh poros engkol menjadi gaya radial (putar).

d) Langkah Buang

Pada langkah ini, gaya yang masih terjadi di flywheel akan menaikkan kembali piston dari TMB ke TMA, bersamaan itu juga katup buang terbuka sehingga udara sisa pembakaran akan di dorong keluar dari ruang silinder menuju exhaust manifold dan langsung menuju knalpot. Begitu seterusnya sehingga terjadi siklus pergerakan piston yang tidak berhenti. Siklus ini tidak akan berhenti selama faktor yang mendukung siklus tersebut tidak ada yang terputus.

Pukat cincin (Purse Seine) adalah alat penangkap ikan dari jaring yang dioperasikan dengan cara melingkari gerombolan ikan hingga alat berbentuk seperti mangkuk pada akhir proses penangkapan ikan. Alat tangkap ini digunakan untuk menangkap ikan pelagis yang bergerombol. Cara pengoperasian pukat cincin adalah dengan melingkari gerombolan ikan, kemudian tali kerut (purse line) ditarik ke dan dari kapal hingga bentuk jaring menyerupai mangkuk. Pukat cincin adalah alat penangkap ikan dari jaring yang dioperasikan dengan cara melingkari gerombolan ikan hingga alat berbentuk seperti mangkuk pada akhir proses penangkapan ikan. Alat tangkap ini digunakan untuk menangkap ikan pelagis yang bergerombol. Cara pengoperasian pukat cincin adalah dengan melingkari gerombolan ikan, kemudian tali kerut (purse line) ditarik ke kapal hingga bentuk jaring menyerupai mangkuk. Purse seine atau pukat cincin merupakan salah satu alat tangkap yang banyak digunakan di dunia. Hal ini dikarenakan dalam satu kali pengangkatan hasil tangkapan dapat mendapatkan jumlah yang banyak. Di Indonesia, jenis alat tangkap yang memiliki konstruksi hampir sama antara lain: pukat langgar, pukat senangin, gae dan giob.

\section{Hasil dan Pembahasan}

Kapal KM. Surya Jaya merupakan kapal ikan jenis pukat cincin atau dalam bahasa asing disebut dengan nama Purse Seine yang beroperasi di perairan Samudera Hindia. Berikut ini merupakan gambar kapal KM. Surya Jaya dapat dilihat pada Gambar 1. Dalam pembahasan terdapat beberapa tahapan dalam pengoperasian mesin pada kapal KM. Surya Jaya. Selain pada tahapan pengoperasian mesin induk, akan dibahas lebih detail pada alat penangkapan purse seine. 


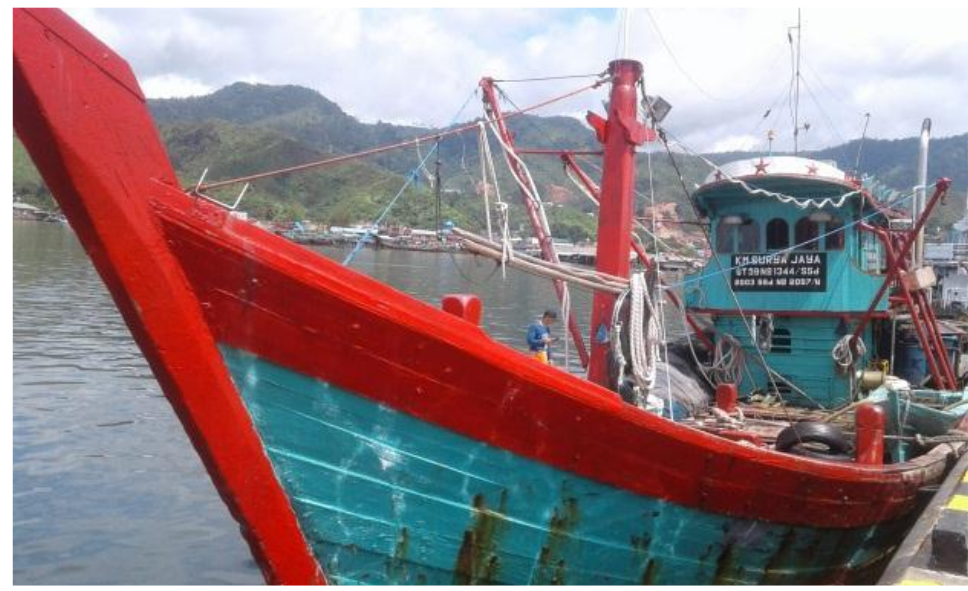

Gambar 1. Kapal KM. Surya Jaya

Dibawah ini merupakan spesfikasi data kapal KM. Surya Jaya sebagai berikut:

Tabel 1. Spesifikasi Data Kapal KM. Surya Jaya

\begin{tabular}{|l|l|}
\hline Nama Kapal & KM. Surya Jaya \\
\hline Jenis Alat Tangkap & Purse Seine \\
\hline Tanda Selar & GT. 59 No. 1344/SSd \\
\hline Gross Tone & 59 \\
\hline Bahan & Kayu \\
\hline Buatan & Sibolga \\
\hline Tahun Pembuatan & 2002 \\
\hline Jenis Penggerak Utama & Motor Diesel \\
\hline Panjang Kapal & $21.40 \mathrm{~m}$ \\
\hline Lebar & $6.30 \mathrm{~m}$ \\
\hline Tinggi & $2.22 \mathrm{~m}$ \\
\hline
\end{tabular}

Sumber: Dokumen Kapal KM. Surya Jaya (2020)

Dalam pembahasan terdapat beberapa tahapan dalam pengoperasian mesin pada kapal KM. Surya Jaya. Selain pada tahapan pengoperasian mesin induk, akan dibahas lebih detail pada alat penangkapan purse seine.

\subsection{Mesin Induk}

Mesin Induk (Main Engine) atau mesin penggerak utama pada kapal dalam arti luas adalah meliputi seluruh unit dalam satu kesatuan pesawat/permesinan yang ditunjuk untuk menggerakkan kapal selalu berada dalam kondisi laik laut (sea worthyness) sehingga kapal dapat dioperasikan untuk pengangkutan laut pada setiap saat dengan kemampuan baik dan normal. Mesin induk yang digunakan saat menggunakan alat tangkap purse seine, dapat dilihat pada gambar 1 dibawah ini dan Tabel 1 yang menunjukkan spesifikasi mesin induknya. Adapun tabel 2 menunjukkan spesifikasi mesin induk yang digunakan, sebagai berikut: 
Tabel 2. Spesifikasi Mesin Induk

\begin{tabular}{|c|c|}
\hline Nama Bagian & Spesifikasi \\
\hline Jenis & Motor Diesel 4 Langkah \\
\hline Merk & Nissan RF 8 \\
\hline Silinder & V-8 \\
\hline Daya Mesin & 140 PS at 2.200 rpm \\
\hline Volume Silinder & $16.991 \mathrm{cc}$ \\
\hline Bore x Stroke & 138 142 mm \\
\hline Pelumas & Sump Basah \\
\hline Bahan Bakar & Solar \\
\hline Sistem Pendingin & Tidak Langsung \\
\hline Sistem Start & Elektrik \\
\hline
\end{tabular}

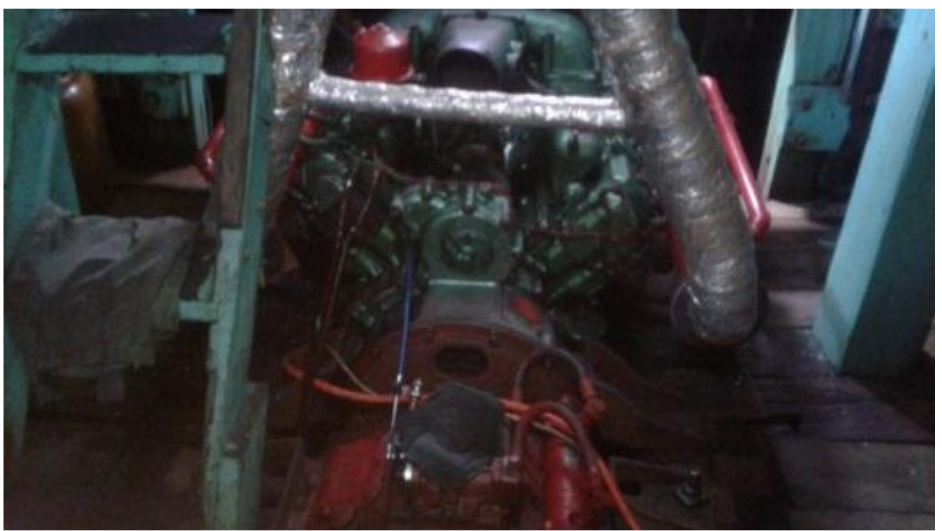

Gambar 2. Mesin Induk

\subsection{Mesin Diesel}

Mesin diesel adalah jenis khusus dari mesin-pembakaran dalam, sesuai dengan namanya mesin pembakaran dalam adalah mesin panas yang didalamnya, energi kimia dari pembakaran dilepaskan didalam silinder mesin, sedangkan golongan lain dari mesin panas- mesin uap - energi yang ditimbulkan selama pembakaran bahan bakar diteruskan terlebih dahulu ke uap, dan hanya melalui uap kerja dilakukukan dalam turbin atau mesin. Tetapi karena tidak ada mesin dengan pembakaran luar, kecuali pengembangan yang terakhir, yaitu turbin gas yang dalam segala hal berada dalam satu kelompok dengan sendirinya; maka pada saat ini terdapat kecenderungan untuk menyebutkan semua mesin panas yang dioperasikan langsung oleh gas pembakaran secara sederhana mesin pembakaran (motor bakar). Karakteristik dari mesin diesel yang membedakan dari motor bakar yang lain adalah: metoda penyalaan bahan bakar, dalam mesin diesel bahan bakar diinjeksikan ke dalam silinder yang berisi udara bertekanan tinggi. Selama kompresi udara dalam silinder maka suhu udara meningkat, sehingga ketika bahan bakar dalam bentuk kabut halus bersinggungan dengan udara panas ini, akan menyala, dan tidak dibutuhkan alat penyalaan lain dari luar. Karena alasan ini mesin diesel juga disebut mesin penyalaan kompresi. 


\subsection{Gear Box Mesin Induk}

Gearbox dalam hal yang bersangkutan dengan bidang kebutuhan industri atau permesinan memiliki fungsi sebagai pemindah tenaga dari tenaga penggerak (mesin diesel atau dinamo motor elektrik) ke mesin yang ingin digerakan. Setidaknya ada 2 alasan kunci mengapa penggunaan Gearbox dalam dunia permesinan memegang peranan penting, pertama fungsi Gearbox utamanya adalah memperlambat kecepatan putaran yang dihasilkan dari perputaran dinamo motor atau mesin diesel dan yang kedua adalah untuk memperkuat tenaga putaran yang dihasilkan oleh dinamo atau diesel. Gearbox merupakan suatu komponen dari suatu mesin yang terdiri dari rumah untuk roda gigi. Komponen ini harus memiliki konstruksi yang tepat agar dapat menempatkan poros-poros roda gigi pada sumbu yang benar sehingga roda gigi dapat berputar dengan baik dengan sedikit mungkin gesekan yang terjadi. Gearbox atau transmisi adalah suatu komponen utama motor yang disebut sebagai sistem pemindahan tenaga, transmisi berfungsi untuk memindahkan dan mengubah tenaga dari motor yang berputar atau hasil putaran dari mesin induk, yang digunakan untuk memutar propeller sehingga kapal dapat terdorong maju atau mundur.

\subsection{Sistem Pendingin Mesin Induk}

Keberadaan mesin pendingin di kapal penangkap ikan sangat dibutuhkan untuk mempertahankan mutu hasil tangkapan. Dalam operasionalnya, mesin pendingin beroperasi selama 24 jam selama kegiatan operasional penangkapan ikan untuk menjamin mutu hasil tangkapan tetap terjaga. Dengan kondisi operasional yang cukup panjang mengakibatkan keandalan komponennya menjadi berkurang seiring bertambahnya waktu pengoperasian. (E., Zaki, Nurfauzi, \& Surya, 2017). Sistem pendinginan yang digunakan diatas kapal KM. Surya Jaya dengan tipe yaitu Sistem Pendinginan Tertutup. Pendinginan tertutup yang dimaksud adalah mesin diesel didinginkan dengan media air tawar dan selanjutnya air tawar yang keluar dari silinder kepala didinginkan melalui cooler air tawar dengan pendingin air laut. Adapun keuntungan dan kerugian pada sistem pendingin mesin induk sebagai berikut:

a) Keuntungannya:

- Dengan media air tawar, maka resiko terhadap korosi dapat dicegah / dihindari

- Pengaturan suhu masuk dan suhu keluar dari air pendinginan lebih mudah diatur lewat cooler

b) Kerugiannya:

- Ketergantungan terhadap persediaan air tawar pendingin

- Sistem penataan pipa menjadi lebih mahal, karena adanya cooler. Tangki ekspansi dan pipapipanya

\subsection{Persiapan Menyalakan Mesin Induk}

Terdapat beberapa langkah yang harus diambil sebelum starter mesin induk, bertujuan agar mesin dapat dioperasikan secara normal dimana mesin tidak terjadi masalah selama mesin dalam keadaan hidup. Berikut beberapa langkah dalam pengoprasian mesin induk sebagai berikut:

a) Sistem bahan bakar

Periksa bagian isi tangki harian bahan bakar, pastikan kondisi minyak tidak tercampur dengan cairan selain bahan bakar seperti air. Dan juga pastikan aliran bahan bakar berjalan dengan normal dengan cara pengecekan terhadap penyaring (filter) dan pipa saluran bahan bakar dalam kondisi terbuka (open). Pemeriksaan bahan bakar bertujuan agar pembakaran dalam mesin berjalan dengan lancar tanpa adanya hambatan selama mesin menyala. Bahan bakar sangat berpengaruh terhadap mesin.

b) Sistem pelumasan

Sistem pelumas yang berkaitan dengan oli dan pompa pelumas harus bekerja dengan baik. Pastikan penyaring (filter) dalam kondisi bersih, karan kondisi terbuka (open), pompa kondisi baik, dan tidak ada kebocoran pada pipa utama maupun pipa kapiler.

Sistem pendingin 
Sistem pendingin yang dipakai pastikan berkerja dengan baik untuk mendinginkan mesin induk. Baik pada komponen pemipaan, pompa, katup (valve distributor), air pendingin dan penyaring air (filter).

\subsection{Perawatan Mesin Induk}

Perawatan atau Pemeliharaan adalah suatu kegiatan yang perlu dilaksanakan terhadap seluruh obyek baik Non - Teknis meliputi manajemen dan sumber daya manusia agar dapat berfungsi dengan baik dan teknis meliputi suatu material atau benda yang bergerak ataupun benda yang tidak bergerak, sehingga material tersebut dapat dipakai dan berfungsi dengan baik serta selalu memenuhi persyaratan internasional. (Imam, 2015)

a) Perawatan Berencana

Perawatan Berencana artinya kita sudah menentukan dan mempercayakan kepada seluruh prosedur perawatan yang dibuat oleh manajemen kerja, melalui Manual Instruction Book, untuk dilaksanakan dengan benar, tepat waktu dan berapapun biaya perawatan yang akan dikeluarkan tidak menjadi masalah, demi mempertahankan operasi kapal tetap lancar tanpa pernah menganggur dan memperkecil/mencegah kerusakan yang terjadi.

b) Perawatan Pencegahan

Pengertian pencegahan lebih baik dari pada menunggu kerusakan yang lebih berat, adalah merupakan suatu pemahaman yang harus bertanggung jawab dalam perawatan. Perawatan pencegahan adalah bagian dari pelaksanaan pekerjaan perawatan berencana yang bertujuan untuk: Memantau perkembangan yang terjadi pada hasil pekerjaan perawatan secara terus-menerus sampai batas nilainilai yang diijinkan. Menemukan kerusakan dalam tahap yang lebih dini, sehingga masih ada kesempatan untuk merencanakan pelaksanaan waktu perawatan. Mencegah terjadinya kerusakan atau bertambahnya kerusakan, yang dapat mengakibatkan terhentinya operasi kapal. Suatu tugas yang perlu dilakukan agar kita dapat menelusuri jalannya kerusakan terhadap nilai keselamatan dan nilai ekonomis kapal.

c) Perawatan dan Perbaikan

Perawatan dan perbaikan adalah bagian dari pelaksanaan pekerjaan perawatan berencana yang bertujuan untuk: Memperbaiki setiap kerusakan yang terpantau, walaupun belum waktunya dilaksanakan perbaikan. Mencegah terjadinya kerusakan atau bertambahnya kerusakan yang lebih besar.

3.7. Mesin Penggerak Generator

Generator salah satu bagian utamanya yaitu rotor. Dimana rotor adalah bagian yang bergerak untuk menghasilkan medan magnet. Rotor bergerak dari mesin penggerak. Pada generator KM. Surya Jaya penggerak generator yaitu menggunakan mesin diesel. Penggunaan mesin diesel sesuai dengan genertor yang di gunakan dimana mesin diesel menghasilkan gerak putaran dari gerak naik turun yang dihasilkan piston. Untuk penjelasan mesin diesel sudah di jelaskan dipenjelasan mesin induk dimana mesin induk yang digunakan adalah mesin diesel. Perbedaannya hanyalah berbeda dengan spesifikasi jumlah piston dan merek mesin. Berikut gambar mesin diesel yang digunakan pada KM. Surya Jaya sebagai mesin penggerak generator.

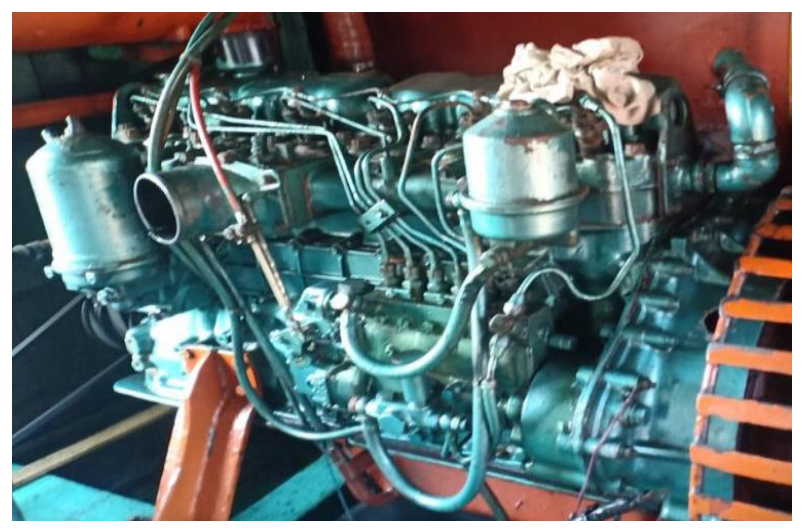

Gambar 3. Mesin Diesel Penggerak Generator 
Adapun spesifikasi generator KM. Surya Jaya dapat dilihat pada Tabel 3.

Tabel 3. Spesifikasi Generator KM. Surya Jaya

\begin{tabular}{|c|c|}
\hline Nama Bagian & Spesifikasi \\
\hline Tegangan & 380 Volt \\
\hline Daya & $50 \mathrm{kVA}$ \\
\hline Frekuensi & $50 \mathrm{~Hz}$ \\
\hline Phase & 3 phase \\
\hline Jenis Generator & AC \\
\hline Mesin Penggerak & Motor Diesel \\
\hline Merk Mesi & Mitsubishi RE6 \\
\hline Jumlah Silinder & 6 \\
\hline Sistem Pelumas & Sump Basah \\
\hline Sistem Start & Elektrik \\
\hline
\end{tabular}

Berikut tahapan persiapan sampai dengan mematikan generator adalah sebagai berikut:

a) Periksa baterai untuk memastikan baterai terisi penuh agar dapat digunakan untuk memulai sistem start pada mesin penggerak generator

b) Pastikan ada atau tidaknya bahan bakar karena apabila tidak dilakukan penambahan bahan bakar akan terjadi kesulitan saat menghidupkan mesin penggerak generator.

c) Periksa tekanan oli dan kekentalannya, apabila tidak sesuai yang dianjurkan, dilakukan penambahan supaya tidak terjadi over heat. Anjuran mengenai tekanan dapat dilihat pada parameter garis yang berada ditutup oli. Apabila oli kurang dari parameter yang ditentukan maka harus dilakukan pengisian ulang hingga mencapai garis parameter yang telah ditetapkan.

d) Periksa kran-kran air pendingin terbuka, agar tidak terjadi penyumbatan. Penyumbatan biasanya terjadi karean kran air pendingin tertutup pada saat mesin dalam keadaan mati.

e) Buka kran air laut, supaya air pendingin mengalir ke seluruh bagian mesin agar terjadi pendinginan yang merata ke seluruh bagian mesin dan tidak terjadi over heat. Over heat biasanya terjadi dikarenakan air pendingin tidak mengalir ke bagian-bagian mesin.

f) Periksa tekanan oli saat posisi running, supaya tidak terjadi hal-hal yang tidak diinginkan seperti tekanan oli rendah yang akan mengakibatkan pergerakan antara bagian mesin yang menimbulkan panas berlebih dari dalam mesin.

g) Periksa tegangan dan ampere pada panel, untuk memastikan tegangan dan ampere tetap sesuai standar. Apabila tegangan dan ampere rendah, periksa kembali generator. Setelah selesai running, matikan mesin pada panel dengan posisi off dan tutup kembali kran air pendingin.

\section{Kesimpulan}

Mesin yang digunakan di kapal KM. Surya jaya baik mesin penggerak utama (main engine) maupun mesin penggerak generator adalah jenis mesin diesel. Dimana, mesin diesel adalah motor bakar dengan proses pembakaran yang terjadi didalam mesin itu sendiri (internal combustion engine) dan pembakaran terjadi karena udara murni dimampatkan (dikompresi) dalam suatu ruang bakar (silinder) sehingga diperoleh udara bertekanan tinggi serta panas yang tinggi, bersamaan dengan itu disemprotkan/dikabutkan bahan bakar sehingga terjadilah pembakaran. Namun, perbedaan antara 
mesin penggerak utama dengan mesin penggerak generator hanyalah terdapat pada sepesifikasi mesin dimana mesin penggerak utama menggunkan jumlah silinder V-8 sedangkan mesin penggerak generator menggunakan jumlah silinder 6 , serta antara mesin penggerak utama dan mesin penggerak generator memiliki sistem pendingin yang sama yaitu sistem pendingin terbuka, memiliki sistem bahan bakar yang sama dialiri dengan bahan bakar solar dari tangki yang sama dan penyaring minyak yang sama.

\section{DAFTAR PUSTAKA}

Ahmad M, Nofrizal. (2009). Tentang Pelapukan Kapal Kayu. Jurnal Perikanan dan Kelautan 14(2):135146.

Ardidja S. 2010. Kapal Penangkapan Ikan. STP Press Jakarta

Deni S. 2015. Karakteristik Mutu Ikan Selama Penanganan Pada Kapal KM. Cakalang. Jurnal IImiah Agribisnis dan Perikanan Ternate 8(2):72.

Direktorat Kredit. 2008. Penangkapan Ikan dengan Purse seine. Bank Indonesia. Hal 29.

Genisa AS. 1999. Pengenalan Jenis-Jenis Ikan Laut Ekonomi Penting di Indonesia. Oseana 24(1):1738.

Imam, F. H. (2015). Perbaikan dan Preawatan Mesin kapal. Universitas Diponogoro. Semarang: academia.edu.

Jufriman, Junaidi, Bukhari. 2015. Studi Pemanfaatan Alat Bantu Penangkapan Ikan Dengan Pukat Cincin (Purse seine) di Sasak Kecamatam Sasak Ranah Pasisie Kabupaten Pasaman Barat. Skripsi Jurusan Pemanfaatan Sumberdaya Perikanan Fakultas Perikanan dan IImu Kelautan Universitas Bung Hatta

Kusairi, A. S. (2018). Motor Bakar. Banjarbaru: HMKB781.

Nur, I. R., Farid, A., \& Apri Arisandi. (2009). Efektivitas Alat Tangkap Mini Purse Seine Menggunakan Sumber Cahaya Berbeda Terhadap Hasil Tangkapan Ikan Kembung. Kelautan, II, 50-59.

Pusdik KP. 2012. Penangkapan Ikan dengan Purse seine. Badan Pengembangan SDM Kelautan dan Perikanan. Hal 35.

Senggetang C, Ondang H, Santoso H. 2011. Teknik Pengoperasin Purse seine di KM. Timur Laut. PT. Pathemaang Raya Bitung Sulawesi Utara.

Surur F. 2015. Purse seine. STP Press. Jakarta. Hal 141.

Wibawa A. 2014. Devinisi Kapal Ikan Purse seine 109 GT KM. Surya Redjeki. 
